\title{
Effect of different dietary fats on oxygen consumption and on serum lipid levels in the baboon (Papio ursinus)
}

\author{
By NERINA SAVAGE AND B. W. GOLDSTONE
}

Department of Physiology and the Nutrition and Metabolism Research Group of the CSIR, University of the Witwatersrand, Johannesburg, South Africa

$$
\text { (Received } 22 \text { Fanuary 1965-Accepted } 23 \text { Fune 1965) }
$$

Under normal conditions, the concentration of cholesterol in the serum of man is regulated at a fairly steady level (Keys, Anderson, Mickelsen, Adelson \& Fidanza, I956).

In herbivores such as the rabbit the regulation is easily overloaded; the addition of large amounts of cholesterol to the diet may result in a tenfold increase in the level of cholesterol in the serum. Even in omnivores such as poultry, dietary cholesterol causes a marked rise in serum cholesterol (March, Biely \& Lindsay, 1964). Also in man, recent experiments have clearly shown that an excess of dietary cholesterol may raise the level of serum cholesterol (Connor, Stone \& Hodges, I964; Connor, Hodges \& Bleiler, I961 $a, b$; Erickson, Coots, Mattson \& Kligman, I963). It can be accepted then that there is a cholesterol-regulating mechanism, easily overloaded in some animals and much more stable in others.

For some years it has been known that an excess of dietary fats can also affect the concentration of cholesterol in the blood; saturated fatty acids raise serum cholesterol level whereas polyunsaturated fatty acids lower it (Kinsell, Michaels, Friskey \& Splitter, 1958; Bronte-Stewart, Antonis, Eales \& Brock, 1956; Ahrens, Hirsch, Insull, Tsaltas, Blomstrand \& Peterson, 1957). Little is known about the mechanism of this effect. We wished to investigate whether excess of saturated or, alternatively, polyunsaturated fat in the diet had some further action on a mammal in addition to the well-known effect on lipid levels. We have therefore studied the effect of such diets on basal oxygen consumption.

We have used primates because, like man, they are omnivorous and are thus more likely to respond similarly to changes in diet. Two groups of baboons were studied. One group was given a diet rich in saturated fatty acids and the other group a diet rich in polyunsaturated fatty acids. We have also determined the concentrations of cholesterol and phospholipid in the serums of the animals on the different dietary treatments.

\section{EXPERIMENTAL}

\section{Diet}

Control. Usually the animals ate the total diet as supplied. This consisted of a cooked mixture containing (\%): 7 I sifted white maize meal, ro dried skim-milk powder, 12 ox liver, 6 beef dripping and I sodium chloride. Approximately $45^{\circ} \mathrm{g}$ of this diet were mixed with water and given to each baboon. In the afternoon raw 
sweet potatoes, carrots, cabbage and oranges were given. The total diet consumed by each animal provided per day $1900-2200 \mathrm{kcal}$ and approximately $330 \mathrm{~g}$ carbohydrate, $50-55 \mathrm{~g}$ protein, $46 \mathrm{~g}$ fat and $0.2 \mathrm{~g}$ cholesterol. Fat contributed about $20 \%$ of the total calories.

Diet $\mathrm{I}$. The cooked mixture contained $(\%): 39$ sifted white maize meal, 16 dried, full-cream milk powder, I I liver, 5.5 beef dripping, 8.5 butter, 9 cream (thick), Io fresh whole egg and I sodium chloride. Approximately $450 \mathrm{~g}$ of this mixture (before addition of water) were given to each baboon in the morning. In the afternoon the baboons were given a small quantity of raw sweet potatoes and carrots only. Cabbage and oranges were omitted; baboons enjoy those and tend to ignore the diet in their favour. The diet consumed by each animal provided per day $1900-2200 \mathrm{kcal}$ and $200 \mathrm{~g}$ carbohydrate, $50-55 \mathrm{~g}$ protein, II7 $\mathrm{g}$ fat and $0.65 \mathrm{~g}$ cholesterol. Fat contributed about $48 \%$ of the total calories.

Diet 2. The cooked mixture contained $(\%): 5 \mathrm{I}$ whole wheat flour, I2 dried skimmilk powder, 12 liver, 24 sunflower-seed oil and I sodium chloride. In the morning each animal was given approximately $45^{\circ} \mathrm{g}$ of the mixture. In the afternoon the baboons were given oranges and cabbage. In this diet it was necessary to reduce the calories contributed by carbohydrate, replacing it by fat. Reduction in the quantity of wheat flour spoilt the consistency of the mixture so that it became unacceptable. Consequently, we lowered the percentage of carbohydrate by omitting carrots and sweet potatoes. Fats, predominately unsaturated fatty acids, provided about $48 \%$ of the total calories.

\section{Animals}

Fifteen healthy adult baboons were used for this investigation. They were divided into two groups. Group I consisted of eight baboons (six females and two males) and group 2 of seven baboons (two females and five males). The animals in group I had either been born or existed for several years in the colony. Those in group 2 had been recently introduced into the colony from the wild state. This may perhaps account for the initial differences in mean cholesterol level and basal oxygen consumption between the two groups (Tables I and 2). The ages of the males and six of the females ranged from 4 to 7 years; two of the females were 12 and $I_{4}$ years. All the animals had been maintained on the control diet for at least 6 months.

\section{Procedure}

Group I. The baboons were first studied while they were given the control diet for a period of I month, measurements being made at weekly intervals, i.e. four determinations per animal. The animals were then given diet I for 4 weeks, measurements again being made at weekly intervals. During this time the contribution made by fat to the total dietary calories was gradually increased from 37 to $48 \%$ by replacing a certain amount of the maize meal and all of the liver by butter, cream and eggs. Thereafter the animals received diet 2 for 9 months. During the Ist month, measurements were made at weekly intervals beginning I week after the introduction of diet 2 
(period 1). Further determinations were made at weekly intervals during the $4^{\text {th }}$ month (period 2) and again during the gth month (period 3 ).

Group 2. Measurements were made at weekly intervals for to weeks while the animals were given the control diet, i.e. a total of ten determinations per animal. Thereafter they received diet I for $9 \frac{1}{2}$ months and measurements were made at two stages during this time: (I) five measurements at weekly intervals, beginning in the 6th month (period I, 6 months), and (2) six measurements, also at weekly intervals, beginning in the gth month (period 2, $9 \frac{1}{2}$ months).

It is not known whether the baboon shows a seasonal variation in oxygen consumption. However, both groups $\mathrm{I}$ and 2 were given diets 2 and $\mathrm{I}$ respectively for a long time. By comparing the values for basal oxygen consumption obtained for these two groups during the 9th month when given both types of dietary fat with those obtained for the animals when given the control diet, we could eliminate any seasonal effect, since measurements were made during the same season. Van Zyl \& Kerrich (1955) have previously shown that there is no seasonal variation in serum cholesterol or phospholipid in the baboon.

\section{Laboratory investigations}

The blood required for the determination of the concentrations of cholesterol and phospholipid in the serum was collected by venepuncture from arm or leg $\mathrm{I} h$ after deep pentobarbitone Na (Sagatal; May and Baker Ltd, Dagenham, Essex) anaesthesia. All animals were in the postabsorptive state. After the blood had clotted, the serum was obtained by centrifugation. Cholesterol was measured spectrophotometrically by the method of van $\mathrm{Zyl} \&$ Kerrich (1955). The extinction values were determined in a model B Beckman spectrophotometer at a wave-length of $660 \mathrm{~nm}$. Phospholipid phosphorus was determined spectrophotometrically by Glick's (1934) modification of the method of Kuttner \& Lichtenstein (1932) for the determination of organically bound phosphorus. The extinction values were determined at $820 \mathrm{~nm}$ after $4^{-20} \mathrm{~min}$ of colour development. Phospholipid values were calculated from phosphorus values by multiplying these by 25 .

Oxygen consumption was determined under deep Sagatal anaesthesia by means of a cuffed endotracheal catheter leading to a Benedict-Roth spirometer. The animals were kept at a constant ambient temperature of $27^{\circ}$. Further details of this method will be given elsewhere (Goldstone \& Savage, 1965 , to be published). Basal oxygen consumption is believed to be either a function of surface area (of which body-weight $\left(W^{3}\right)$ is an approximate measure) or alternatively as a function of $W^{z}$ (Kleiber, 196I). To make allowance for any weight change we have divided the animal's oxygen consumption by its $W^{3}$. Our results, of course, would be equally significant if we had expressed the values as oxygen consumption $\div W^{4}$.

\section{Statistical analysis}

The significance of the difference observed after change in diet was examined by means of the $t$ test described by Hill (I96I). 
RESULTS

Weight changes

Two of the females in group I and the two in group 2 lost weight when they were given the high-fat diet; all the males gained weight when they were given the high-fat diet, but the increase in weight was most pronounced in the group given the diet containing saturated fat (Table $\mathrm{r}$ ).

\section{Control diet}

Serum lipids and basal oxygen consumption

Table I shows the mean values for basal oxygen consumption of the two groups of baboons. Table 2 shows the mean values for the concentrations of cholesterol and phospholipid and the cholesterol:phospholipid ratio in the serums of the two groups of animals.

\section{Change from control diet to diet 1 (containing saturated fat)}

Group I. During the 4 weeks when the animals were given diet I there was a significant increase $(0.001<P<0.005)$ in the mean concentration of cholesterol in the serum for the group (Table 2). The concentration of phospholipid in the serum and basal oxygen consumption were not significantly affected (Tables I and 2).

Group 2. These animals received diet I for a much longer period than did the animals in group I. At the end of 6 months (period I, Tables $I$ and 2) significant increases occurred in the group means for serum cholesterol $(0.005<P<0.01)$ and phospholipid $(0.05<P<0.1)$. The change in diet resulted in a marked decrease $(0.005<P<0.0 \mathrm{I})$ in basal oxygen consumption in all seven animals at this stage. After $9 \frac{1}{2}$ months on diet I (period 2, Tables I and 2) the concentrations of cholesterol and phospholipid in the serum of all the animals except one appeared to be reverting towards their normal values, though the mean concentration of cholesterol in the serum was still above normal. The depression in basal oxygen consumption observed during period $I$ was maintained in all the animals during period 2 and was again significantly less $(0.001<P<0.005)$ than that observed for the animals when given the control diet. Summarizing this effect of the prolonged administration of a diet rich in saturated fatty acids, we can say that there was a steady fall in basal oxygen consumption throughout. Phospholipid and cholesterol levels in the serum at first increased, though later they partly reverted.

\section{Comparison of effects of a high-fat diet (polyunsaturated fat)}

Group I. During all the periods of the experiment when the baboons were given diet 2 the concentration of phospholipid in the serum was significantly lower than that in the serum of the animals on the control diet (Table 2). On the other hand, the serum cholesterol levels of the baboons given diet 2 for I or 4 months were not significantly different from the serum cholesterol level found for the animals when they were given the control diet. However, after 9 months on diet 2 the serum cholesterol had decreased to a level that was significantly lower than that observed 
Vol. 19

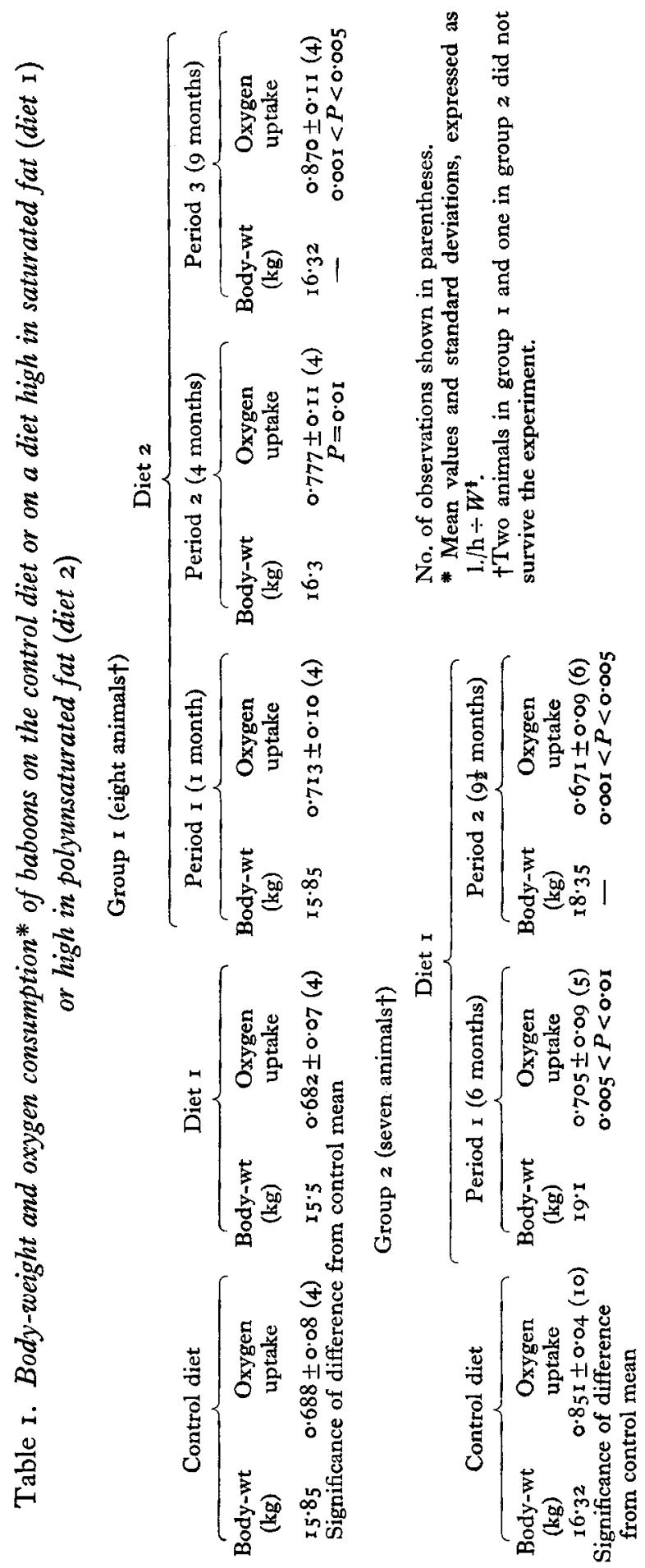




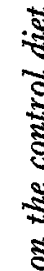

है

है है

竎

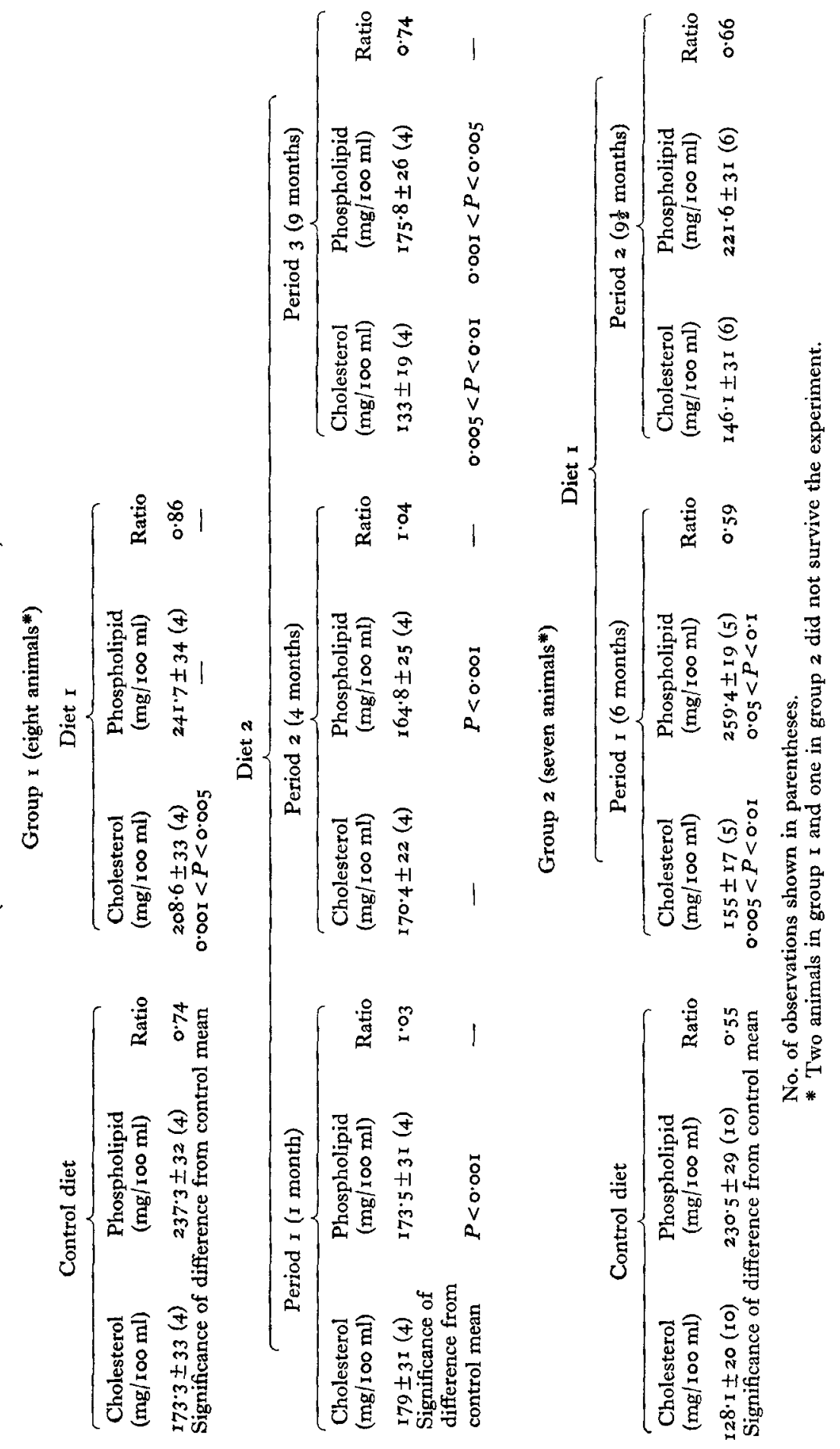

कิ อ

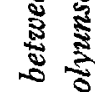

कूष

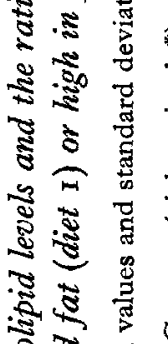

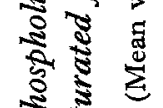


for the animals on the control diet. The basal oxygen uptake of the baboons during the Ist month on diet 2 was not significantly different from that of the animals on the control diet (Table $\mathrm{I}$ ). After 4 or 9 months on diet 2 the basal oxygen consumption increased to levels that were significantly higher than that observed for the animals when they were given the control diet. To summarize the effect of the prolonged administration of a diet rich in polyunsaturated fatty acids subsequent to a diet rich in saturated fatty acids: there was an early and sustained fall in the mean concentration of phospholipid in the serum; the mean concentration of cholesterol in the serum returned to control values during the first 4 weeks and subsequently decreased slowly; the basal oxygen consumption eventually increased significantly.

Table 2 shows the cholesterol:phospholipid ratios in the serum for both groups of animals when they were given the control or high-fat diets. It is noteworthy that both types of dietary fat increased the mean cholesterol:phospholipid ratio in the serum. This increase, though marked in the animals given diet 2, was not sustained and the cholesterol:phospholipid ratio reverted to normal after 9 months. With diet $\mathrm{I}$ however the ratio remained elevated.

\section{DISCUSSION}

Diet I (containing a high level of saturated fat) caused changes in the concentrations of cholesterol and phospholipid in the serum and in the basal oxygen consumption. Diet 2 (containing a high level of polyunsaturated fat) caused changes in blood lipids and basal oxygen consumption, but in the opposite direction. Various hormones are known to influence blood lipid levels: thyroxine (Malmros \& Swahn, 1953; Strisower, Gofman, Galioni, Almada \& Simon, 1954), growth hormone (Engel, Hallman, Siegel \& Bergenstal, 1958), lipid-mobilizing factor (LM) of the neurohypophysis (Seifter \& Baeder, 1957) and insulin, glucagon, catechol amines, adrenal corticoids and sex hormones (Oliver \& Boyd, I956).

It is natural to ask if one of these hormones is involved in the mechanism whereby different dietary fats influence lipid levels and oxygen consumption.

Of all these possible hormone mediators, thyroxine appears to deserve first consideration since its effect on blood lipid levels is similar to that brought about by ingestion of polyunsaturated fats. In man both thyroxine and polyunsaturated fats cause: (I) increased degradation of cholesterol to bile acids and (2) depression of $\beta$ - and $\alpha$-lipoproteins with resultant relative stability of the cholesterol:phospholipid ratio (Olson \& Vester, 1960; Strisower, 1959; Kinsell et al. 1958; Lewis, 1958; Gordon, Lewis, Eales \& Brock, 1957).

A further point of similarity, as we have now shown in the baboon, is that polyunsaturated fatty acids in the diet raise the basal metabolic rate. We are therefore planning to study thyroxine output in animals given different dietary fats.

Swank \& Nakamura (1960) have shown that in the rat a diet high in saturated fat causes agglutination of red cells and immediate interference with oxygen transfer to the brain. It seems unlikely that this effect could explain our results with experimental baboons since the effects on BMR developed slowly over several months.

Panos, Finerty, Klein \& Wall (1958) found that the basal oxygen consumption of 
rats increased when they were given a fat-free diet; control rats given a diet containing $30 \%$ polyunsaturated fat showed no increase. Our results with baboons are in direct contrast to these findings. However, the tests on rats were not conducted at a standard (critical) ambient temperature. Moreover, the effects of changes in the type and level of dietary fat on blood lipids in rats are often the reverse of those observed in primates (Olson \& Vester, I960).

When the baboons were given the diet containing polyunsaturated fat the changes in level of phospholipids in the serum occurred more rapidly than changes in the other lipid levels. This is in contrast with results on human volunteers eating a similar long-term diet (Antonis \& Bersohn, 1962). In these volunteers, maximum changes in blood cholesterol levels occurred rapidly (within a few weeks); pronounced changes in the levels of phospholipid in the serum took 2 years to develop. With baboons the opposite seems to occur; maximum change in the level of serum phospholipid occurred quickly, whereas marked changes in the level of serum cholesterol developed slowly. The human volunteers, given the diet containing polyunsaturated fat, at first showed a depression in the cholesterol:phospholipid ratio in the serum because of the early fall in cholesterol level. However, after $\mathrm{I} \frac{1}{2}$ years on this diet, maximum fall of the level of phospholipid in the serum had occurred; and this raised the cholesterol:phospholipid ratio nearly to unity. Thus, although men and baboons as primates have many physiological mechanisms in common, this study shows that there is a striking difference in the effect of diet on the cholesterol:phospholipid ratio in the plasma of these two species.

All the changes that resulted from alterations in the dietary fat were more marked in adult males than in females. In man, too, it is generally accepted that serum lipid levels are more susceptible to alteration in the male than in pre-menopausal females; the difference is probably due to oestrogen levels (Oliver \& Boyd, 1956).

Finally, the weight gain of the baboons on the polyunsaturated-fat diet should be noted: it was less than the weight gain on the saturated-fat diet. This is perhaps to be correlated with the high basal oxygen consumption of the animals on the former diet. This fact may have application in practical animal nutrition and in the field of human dietetic therapy.

\section{SUMMARY}

I. A group of eight baboons (group I) was fed on a diet rich in saturated fat for I month, during which time oxygen consumption and the levels of cholesterol and phospholipid in the serum were determined. The concentration of cholesterol increased significantly.

2. A second group of seven baboons was given the same high-fat diet for 9 months. After 6 months the serum cholesterol and phospholipid levels rose significantly. The basal oxygen consumption fell significantly. After 9 months, the cholesterol and phospholipid values appeared to be reverting towards normal basal values. The depression of oxygen consumption persisted.

3. The original baboons of group I were transferred for $9 \frac{1}{2}$ months to a diet containing polyunsaturated fat. At the end of $I$ month the phospholipid levels had dropped significantly; these low phospholipid levels were maintained throughout. 
After 4 months cholesterol levels began to fall. The rise in the basal oxygen consumption was significant at this stage. After $9 \frac{1}{2}$ months both the cholesterol and phospholipid levels were significantly lowered. The oxygen consumption remained significantly increased.

4. The cholesterol:phospholipid ratios of both groups of animals increased with either type of fat diet. The cholesterol: phospholipid ratio, however, remained elevated in the group receiving the diet high in saturated fat, but eventually reverted to normal in those animals receiving the polyunsaturated-fat diet.

5. For all the observed variables, a polyunsaturated-fat diet closely imitates the action of thyroxine and a saturated-fat diet has the reverse action. It was decided for future study to use further tests of thyroxine output in this experimental situation.

6. The effect of these diets on lipid levels is well known in man and other mammals. In addition, it was noted that these diets had a marked effect on basal oxygen consumption.

We wish to thank Mr E. Allen, Mrs R. Smith and Miss M. J. Bertels for their whole-hearted technical assistance. At all times Professor C. H. Wyndham, Professor C. P. Luck and Professor P. R. Levy have given their advice and help in this work. The CSIR of South Africa has contributed to the cost of this project.

\section{REFERENCES}

Ahrens, E. H. Jr., Hirsch, J., Insull, W. Jr., Tsaltas, T. T., Blomstrand, R. \& Peterson, L. (1957). Lancet, i, 943 .

Antonis, A. \& Bersohn, I. (1962). Am. \%. clin. Nutr. 1o, 484.

Bronte-Stewart, B., Antonis, A., Eales, L. \& Brock, J. F. (1956). Lancet, i, 521.

Connor, W. E., Hodges, R. E. \& Bleiler, R. E. (I96I a). F. Lab. clin. Med. 57, 33r.

Connor, W. E., Hodges, R. E. \& Bleiler, R. E. (I96I b). F. clin. Invest. 40, 894.

Connor, W. E., Stone, D. B. \& Hodges, R. E. (1964). F. clin. Invest. 43, I69I.

Engel, H. R., Hallman, L., Siegel, S. \& Bergenstal, D. M. (1958). Proc. Soc. exp. Biol. Med. 98, 753. Erickson, A., Coots, A. H., Mattson, F. H. \& Kligman, A. M. (r963). Circulation, 28, 656.

Glick, D. (1934). F. Lab. clin. Med. r9, ro12.

Gordon, H., Lewis, B., Eales, L. \& Brock, J. F. (1957). Nature, Lond., r80, 923.

Hill, A. B. (1961). Principles of Medical Statistics, 7 th ed., p. 148. London: The Lancet Ltd.

Keys, A., Anderson, J. T., Mickelsen, O., Adelson, S. F. \& Fidanza, F. (1956). F. Nutr. 59, 39.

Kinsell, L. W., Michaels, G. D., Friskey, R. W. \& Splitter, S. (1958). In Essential Fatty Acids: Proceedings of the Fourth International Conference on Biochemical Problems of Lipids, Oxford, 1957, p. I25. [H. M. Sinclair, editor.] London: Butterworth's Scientific Publications.

Kleiber, M. (196r). The Fire of Life. Ch. 10, p. 191. London and New York: John Wiley \& Sons Inc.

Kuttner, T. \& Lichtenstein, L. (1932). F. biol. Chem. 95, 66r.

Lewis, B. (1958). Lancet, i, rogo.

Malmros, H. \& Swahn, B. (1953). Acta med. scand. 145, 36r.

March, B. E., Biely, J. \& Lindsay, O. B. (1964). Can. J. Biochem. Physiol. 42, 121.

Oliver, M. F. \& Boyd, G. S. (1956). Circulation, r3, 82.

Olson, R. E. \& Vester, J. W. (1960). Physiol. Rev. 40, 677.

Panos, T. C., Finerty, J. C., Klein, G. F. \& Wall, R. L. (1958). In Essential Fatty Acids: Proceedings of the Fourth International Conference on Biochemical Problems of Lipids, Oxford, 1957, p. 205. [H. M. Sinclair, editor.] London: Butterworth's Scientific Publications.

Seifter, J. \& Baeder, D. H. (1957). Proc. Soc. exp. Biol. Med. 95, 318.

Strisower, B., Gofman, J. W., Galioni, E. F., Almada, A. A. \& Simon, A. (I954). Metabolism, 3, 2 I8. Strisower, E. H. (r959). In Hormones and Atherosclerosis, p. 3I5. [G. Pincus, editor.] New York: Academic Press Inc.

Swank, R. L. \& Nakamura, H. (1960). Am. F. Physiol. 198, 2 г7.

van Zyl, A. \& Kerrich, J. E. (1955). S. Afr. Y. med. Sci. 20, 97. 